\title{
Communicating through Translation with Arab Migrants in Australia
}

\author{
Raymond Chakhachiro \\ School of Humanities and Communication Arts \\ Western Sydney University \\ Sydney, Australia
}

\begin{abstract}
Translation in countries with a large migrant population plays a significant role in providing social services and in helping migrants and refugees who do not speak the language of their host countries be aware of their rights and responsibilities. This paper investigates the translation of community texts into Arabic in Australia, which aims at providing social justice to migrants and maintaining their languages and cultures. Despite the existence of an established national body and institutions that accredit and train translators, translation for Arab migrants still suffers from problems that hinder these goals and render lip service to the Arabic language because of the prevalence of subjective interference and inappropriate transfer process. This paper discusses the challenges, and investigates the competency of translators and their ability to deal with the cultural dominance of the host country. It investigates and suggests solutions to the factors that impact on the process of producing accurate and accessible translation. As such, it addresses the peculiarities of the types, styles and language of texts requiring translation, as well as the peculiarities of the Australian public service system and terminologies.
\end{abstract}

Keywords: accessibility, accuracy, community translation, interference, and translation quality

Cite as: Chakhachiro, R. (2017). Communicating through Translation with Arab Migrants in Australia. Arab World English Journal for Translation \& Literary Studies, 1(4).

DOI:http://dx.doi.org/10.24093/awejtls/vol1no4.1 